\title{
FATTY ACIDS COMPOSITION IN MACADAMIA SEDES OIL (MACADAMIA INTEGRIFOLIA) FROM ECUADOR
}

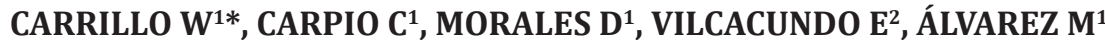

${ }^{1}$ Laboratory of Functional Foods, Faculty of Foods Science and Engineering, Technical University of Ambato, Av. Los Chasquis y Rio Payamino, Campus Huachi, CP 1801334, Ambato, Ecuador. ${ }^{2}$ Faculty of Health and Human Sciences, Bolivar State University, Academic Campus "Alpachaca” Av. Ernesto Che Guevara s/n y Av. Gabriel Secaira, EC. 020150, Guaranda, Ecuador. Email: wi.carrillo@uta.edu.ec
\end{abstract}

Received: 11 October 2016, Revised and Accepted: 03 November 2016

ABSTRACT

Objective: The aim of this study was to determine the fatty acids composition in a Macadamia seeds oil sample cultivated in Ecuador.

Methods: Macadamia oil was obtained of Macadamia seeds using the cold pressing method. Fatty acids analysis was performed using the gas chromatography method with a mass selective detector and using the database library NIST14.L to identify the compounds.

Results: Macadamia seeds have a high content of unsaturated fatty acids with $41.36 \%$ of oleic acid. Macadamia seeds oil has $37.77 \%$ of polyunsaturated fatty acids of which 3.79\% $\omega-6 \alpha$-linoleic and 33.98\% of $₫ 3 \alpha$-linolenic. Macadamia seeds only have $9.33 \%$ of palmitic acid.

Conclusions: Macadamia seeds are a good source of monounsaturated fatty acids with a good content of $₫-6 \alpha$-linoleic. This profile enables their use as a good and healthy oil to be used in the food industry in Ecuador.

Keywords: Macadamia, Macadamia integrifolia, Fatty acids, Gas chromatography-mass selective detector, Methyl ester, Omega acids.

(C) 2017 The Authors. Published by Innovare Academic Sciences Pvt Ltd. This is an open access article under the CC BY license (http://creativecommons. org/licenses/by/4. 0/) DOI: http://dx.doi.org/10.22159/ajpcr.2017.v10i2.15618

\section{INTRODUCTION}

Macadamia is a genus of flowering plants belonging to the Proteaceae family, being cultivated for its edible kernels. There are four species of Macadamia; all species are typical in subtropical rainforests along the East coast of Australia. Two of the species, Macadamia integrifolia, and Macadamia tetraphylla, generate edible nuts and are of commercial importance in the world [1,2]. M. integrifolia, commonly known as the smooth-shell Macadamia, provides kernels with higher quality, whereas M. tetraphylla, known as the rough-shell Macadamia, is more adaptable and can grow more easily at low temperatures or over a wider range of temperatures [3-5]. The other two species, Macadamia ternifolia and Macadamia jansenii, are inedible, as they contain cyanogenic glycosides which are toxic and they are not apt to human consume [6].

Macadamia is the only Australian plant that has been domesticated on a commercial scale as a food crop in other countries. Macadamia is cultivated mainly in Australia, the USA (Hawai and California) and South Africa. There are also expanding industries in Brazil, Guatemala, and Kenya, and smaller industries in New Zealand, Malawi, Paraguay, Ecuador, and other countries [7-9]. The worldwide production of Macadamia sp. is approximately 44,000 metric tons (kernel), 86\% of which come from Australia, South Africa, Kenya, the United States, and Malawi. Australia is the World's largest producer, with approximately 14,100 metric tons [10]. M. integrifolia contain approximately $70 \%$ of oil and its oil is the most highly monounsaturated fatty acids, which possibly help lower blood cholesterol, and its regular consume can help to reduce the risk of heart disease. M. integrifolia has a high oleic acid content and low level of saturated and polyunsaturated fatty acids. The low content of polyunsaturated fatty acids (PUFAs) produces good stability and less susceptibility to Macadamia seed oil oxidation, as PUFAs are more susceptible to oxidative degradation. Macadamia seed oil has a high content of monounsaturated fatty acids. Studies have been conducted to evaluate the effect of nut consumption in the human health $[11,12]$. The Macadamia kernel is a rich source of lipids, proteins, and important micronutrients. However, its chemical composition can vary considerably depending on the variety, seed maturity, geographic location and growth conditions, such as quality of soil [7].

The aim of this work was to characterize the composition of fatty acids methyl esters (FAMEs) present in Macadamia oil samples cultivated in Ecuador using the gas chromatography-mass selective detector (GC-MSD).

\section{METHODS}

\section{Oil extraction}

Macadamia was obtained in the supermarket of Ecuador. Macadamia oil sample was obtained from Macadamia seeds using the cold pressed method. Oil was then stored at $4.0 \pm 2{ }^{\circ} \mathrm{C}$. Oil extraction was conducted using a Soxhlet apparatus for approximately $5 \mathrm{hrs}$ with hexane as solvent, with a solid to solvent ratio of $1 / 7 \mathrm{~m} / \mathrm{v}$. After the extraction process, the flask contents were filtered, and the liquid fraction containing the lipid extract and solvent was poured into a $250 \mathrm{~mL}$ flask of a rotary film evaporator to remove the solvent. The obtained oil was collected, evaporated under nitrogen, weighed, and stored in sealed amber glass vials at $-20^{\circ} \mathrm{C}$ until analysis [13].

\section{Fatty acids analysis by GC-MSD}

The fatty acid composition of oil extracted from Macadamia seeds was analyzed by injecting FAMEs [14] into an Agilent Technologies 7980 A system gas chromatography (Agilent, Santa Clara, CA) equipped with a MSD 5977A GC/MSD, an auto-sampler 7693, column $(60 \mathrm{~m} \times 250 \mu \mathrm{m} \times 0.25 \mu \mathrm{m}$, Agilent 122-7062). The oven temperature was programmed as follows: From $80^{\circ} \mathrm{C}$; ramp 1: To $100^{\circ} \mathrm{C}$ at $20^{\circ} \mathrm{C} /$ minute during 1 minute; ramp 2 : At $200^{\circ} \mathrm{C}$ at $25^{\circ} \mathrm{C} /$ minute during 10 minutes; ramp 3: At $250^{\circ} \mathrm{C}$ at $2^{\circ} \mathrm{C} /$ minute. The injector and detector temperatures were set at $250^{\circ} \mathrm{C}$. Helium was used as carrier gas at a linear flow velocity of $1.4 \mathrm{~mL} /$ minute. 


\section{RESULTS}

Fig. 1 shows the commercial Macadamia seeds without skin before extraction oil by cold pressed.

Macadamia oil sample was obtained using the cold pressing method; fatty acids were subsequently methyl esterified (FAMEs). FAMEs from Macadamia oil were identified using the GC/MSD analytical method. The spectrum of precursor ions produced in the ionization of the mass apparatus was compared with similar spectrums available in the three different databases of the Library NIST14. L. Eight majority peaks were identified with their associated retention time: C16:0 with a retention time of 19.379 minutes; C16:1 with a retention time of 20.314 minutes; C18:0 with a retention time of 26.056 minutes; C18: 1 with retention of 26.928 minutes; C18:2 with retention time of 27.167 minutes; C18:3 with retention time of 28.677 minutes; C20:0 with retention time of 33.468 minutes and finally C20:1 with a retention time of 34.350 minutes (Fig. 2).

The concentration of FAMEs was calculated with a peak area percentage. FAMEs were characterized: C16:0 palmitic acid with $9.11 \%$ of fatty content, C16:1 palmitoleic with $12.48 \%$ of fatty content, C18:0 stearic acid with $3.93 \%$ of fatty content, C18:1 oleic acid with $63.36 \%$ of fatty content, C18:2 linoleic acid (LA) with $3.79 \%$ of fatty content, C18:2 LA with $3.22 \%$ of fatty content, C18: 3 linolenic acid with $1.69 \%$ of fatty content; C20:0 arachidic acid with $3.31 \%$ of fatty content, and finally, C20:1 gadoleic acid with $2.90 \%$ of fatty content (Table 1).

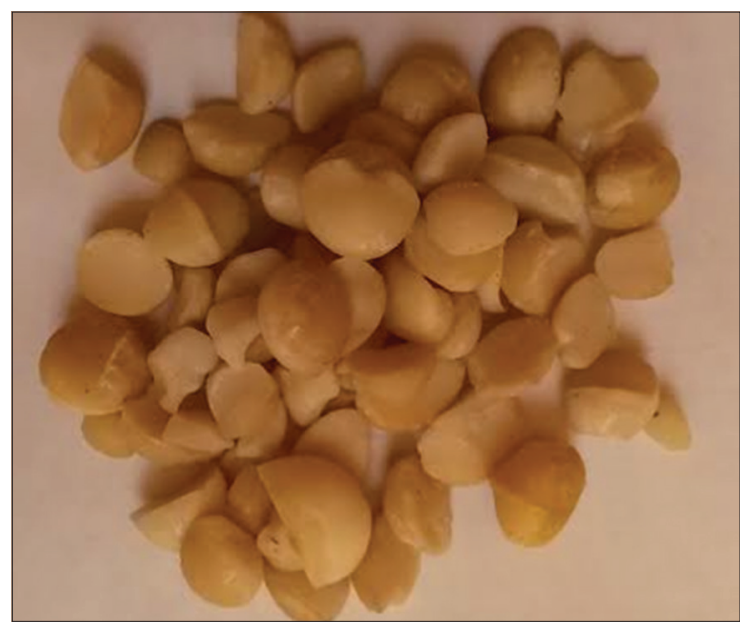

Fig. 1: Macadamia seeds without skin

\section{FAMEs}

When the Macadamia fatty acid composition is compared to some common vegetable oils, it can be seen that olive oil has a high content of mono-unsaturated fatty acids, C18:1 named oleic acid with 77.6\% of oleic acid. It can be seen that Macadamia oil from Ecuador has a high content of mono-unsaturated fatty acids with a content of $63.36 \%$ of oleic acid. Macadamia oil has also a low content of PUFAs with 5.01\%. Olive oil contains few $₫-6$ and $₫-3$ fatty acids with $9.0 \%$ and $1.0 \%$, respectively, and Macadamia oil contain $3.22 \%$ of $₫-6$ and $1.79 \%$ of $๑-3$ (Table 2).

Many of the chronic conditions, cardiovascular diseases, diabetes, cancer, obesity, autoimmune diseases, rheumatoid arthritis, asthma, and depression, are associated with an increased production of thromboxane A2, leukotriene B4, IL- $1 \alpha$, IL-6, tumor necrosis factor, and C-reactive protein. The previous molecule levels increase with increases in $₫-6$ fatty acid intakes and decrease with increases in $๑-3$ fatty acid intakes $[15,16]$.

\section{DISCUSSION}

Lipids are a major component of the human diet. Essential fatty acids (EFA) are crucial dietary constituents for normal growth, development, and maintain of internal homeostasis. High quantities of EFA may be found in plant seeds distributed in many regions of the world such as South America in plants such as sachainchi (Pluketenia volubilis), ungurahui (Oenocarpus bataua) and Macadamia (Macadamia integrofolia). These plants can provide oils with a high concentration of monounsaturated fatty acids, that can help preventing cardiovascular diseases through different mechanisms [17]. The consumption of saturated fat in Ecuador is high, and the balance of $₫ 3$ and $₫ 6$ is not correct in many processed foods. Dietary EFA includes LA, an n-6 FA, and alpha-linolenic acid (ALA), an n-3 FA. LA and ALA cannot be synthesized by the human organism being necessary to supply them through foods in diet intake [18-20]. More importantly, EFA are metabolized with very long chains (VLC) PUFAs. For instance, LA is converted to VLCPUFA arachidonic acid (AA), and ALA is converted to both VLCPUFAs eicosapentaenoic acid and docosahexaenoic acid. Both EFA and their associated VLCPUFA metabolites are important for different organism functions, including growth, immunity function, and cognitive development [21,22]. It is known that nuts are energy dense and provide 23.4 to $26.8 \mathrm{~kJ} / \mathrm{g}$ of calories with a high-fat content (45-75\% of weight), but mostly unsaturated fatty acids [23]. Results of different epidemiologic studies have suggested that there may be a connection between frequent nut consumption and decreased incidences of several chronic diseases [24]. Recent emerging scientific studies have demonstrated that the bioactive constituents of nuts have cardioprotective, antiobesity, anticancer, and antioxidant effects mediated by different mechanisms in the human body [25,26].

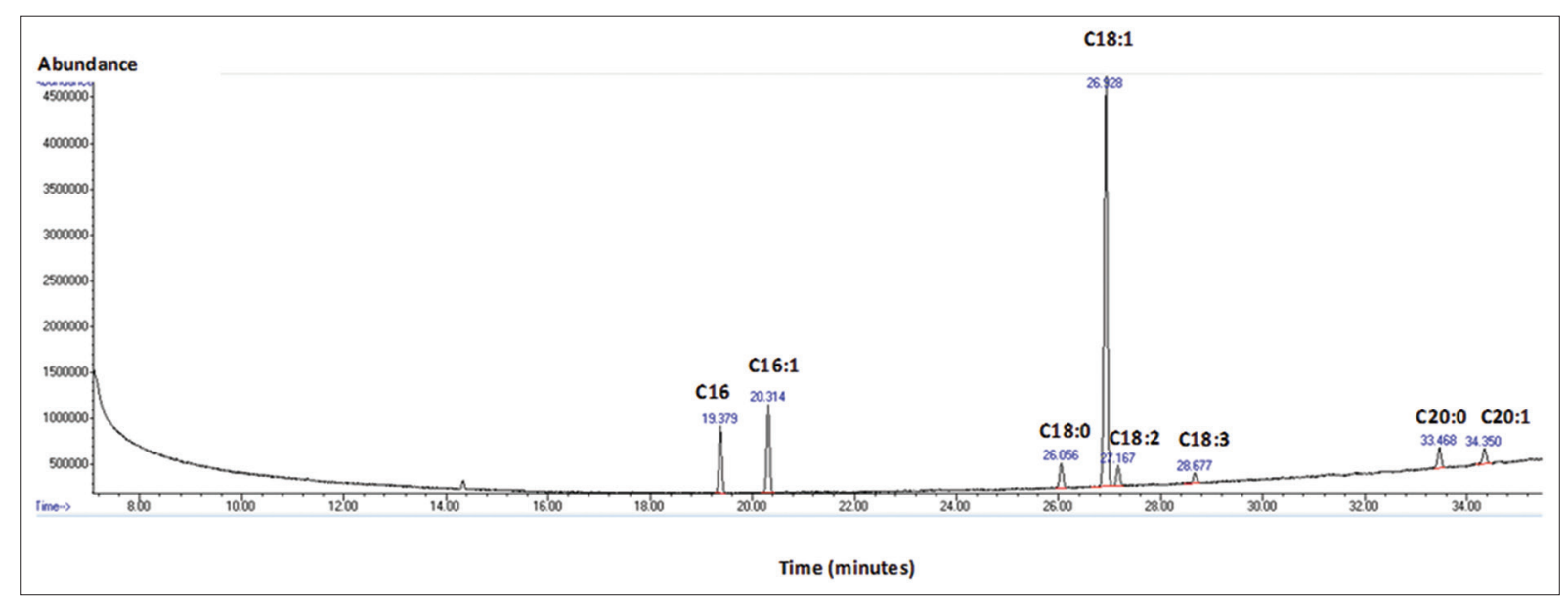

Fig. 2: Gas chromatography mass selective detector analysis of fatty acids present in Macadamia oil sample 
Table 1: Fatty acids composition of Samboseeds oil sample from Ecuador by GC/MSD analysis and their percentage

\begin{tabular}{|c|c|c|c|}
\hline $\begin{array}{l}\text { Retention time } \\
\text { (minutes) }\end{array}$ & $\begin{array}{l}\text { Peak area } \\
\text { ratio } \%\end{array}$ & $\begin{array}{l}\text { Carbon number: } \\
\text { Double bound }\end{array}$ & FAMEs name \\
\hline 19.379 & 9.11 & C16:0 & Palmitic acid \\
\hline 20.314 & 12.48 & C16:1 & Palmitoleic acid \\
\hline 26.056 & 3.22 & C18:0 & Stearic acid \\
\hline 26.928 & 63.36 & $\Delta 9 \mathrm{C} 18: 1$ & Oleic acid \\
\hline 27.177 & 3.22 & $\Delta 9,12 \mathrm{C} 18: 2$ & Linoleic acid \\
\hline 28.677 & 1.79 & $\Delta 9,12,15 \mathrm{C} 18: 3$ & Linolenic acid \\
\hline 34.350 & 2.90 & C20:1 & Gadoleic acid \\
\hline
\end{tabular}

FAMEs: Fatty acids methyl esters

Table 2: Fatty acid composition (\%) of eight vegetable oils

\begin{tabular}{|c|c|c|c|c|c|c|c|c|c|}
\hline Reference & Vegetable oil & C16:0 & C16:1 & C18:0 & C18:1 & C18:2 & C18:3 & C20:0 & C20:1 \\
\hline 9 & Olive oil & 13.8 & 1.4 & 2.8 & 71.6 & 9.00 & 1.0 & NR & NR \\
\hline 9 & Sunflower oil & 5.2 & 0.1 & 3.7 & 33.7 & 56.5 & 0.0 & NR & NR \\
\hline 9 & Palm oil & 44.8 & 0.0 & 4.6 & 38.9 & 9.5 & 0.4 & NR & NR \\
\hline 9 & Soybean Oil & 10.1 & 0.0 & 4.3 & 22.3 & 53.7 & 8.1 & NR & NR \\
\hline 9 & Corn oil & 11.6 & 0.0 & 2.5 & 38.7 & 44.7 & 1.4 & NR & NR \\
\hline 10 & Sacha inchi oil & 3.98 & 0.0 & 3.12 & 8.58 & 34.98 & 47.04 & 0.0 & 0.0 \\
\hline 11 & Sambo oil & 9.33 & 0.0 & 6.84 & 41.36 & 33.98 & 0.0 & 0.0 & 0.0 \\
\hline
\end{tabular}

The American Heart Association, the Canadian Cardiovascular Society [27], the US Food and Drug Administration (US Food and Drug Administration, 2003) [28], and the US Department of Agriculture (US Department of Health and Human Services and US Department of Agriculture, 2015) have recommend the regular consumption of nuts to the general population, in the context of a healthy diet for their good properties [29].

The results obtained in this study are in accordance to fatty acids levels from Macadamia seeds reported in different studies in the science literature. It has been reported that in Macadamia has a high content of monounsaturated fatty acids such as oleic acid, Venkachalam, and Shate, 2006 reported $58.51 \%$ of oleic acid, $1.81 \%$ of $₫-6$, and $2.58 \%$ of ๑-3 from M. integrofolia [30].

Phatanayinde et al., 2012 reported $59.4 \%$ of oleic acid, $2.4 \%$ of $₫ 6 \%$ and $0.13 \%$ of $\omega-3$ from M. integrofolia [31]. On the other hand, Kaijser et al., 2000 reported $40.55 \%$ of oleic acid, $2.63 \%$ of $₫ 6 \%$, and $0.17 \%$ of $₫-3$ from Macadamia tetraphyla [32]. Firestone, 2006 reported 56\% of oleic acid and $2.0 \%$ of $\Phi-6$ from $M$. tetraphyla and $59 \%$ of oleic acid and $3.0 \%$ of $₫-6$ from $M$. ternifolia [33]. All Macadamia oil studied by the previous authors presented a high content of oleic acid between $40.55-59.0 \%$ of oleic acid out of total fatty acids. In this study, the Macadamia seed oil presented a similar high content of oleic acid and a low content of linoleic and linolenic acids. Oleic acid is recommended by Food and Drugs Administration (FDA) as an intake of monounsaturated fatty acids to reduce the risk of cardiovascular diseases. In 2004, the FDA authorized a health claim on olive oil on coronary heart disease: "Limited and not conclusive scientific evidence suggests that eating about two tablespoons ( $23 \mathrm{~g}$ ) of olive oil daily may reduce the risk of coronary heart disease due to the monounsaturated fat in olive oil. To achieve this possible benefit, olive oil is to replace a similar amount of saturated fat and not increase the total number of calories you eat in a day" (CFSAN/Office of Nutritional Products, 2004)[34]. A recent study from the European Food Safety Authority (EFSA) supports the effects of virgin olive oil phenols on low-density lipoprotein (LDL) oxidation (EFSA, 2011) [35]. The extra virgin olive oil contains monounsaturated fatty acid (oleic acid) and phenols compounds with antioxidant capacity. It is known that oxidation of LDL cholesterol is a key factor important in the development of atherosclerosis, promoting the formation of foam cells in the subendothelial space of the vascular wall. Oleic acid and phenols help to prevent this oxidation when incorporated in the human diet daily [36]. Macadamia seed oil has a good proportion of oleic acid. Macadamia seed oil can be a good alternative in Ecuador to be used in the food industry due to its high nutritional quality and its high content of oleic acid.

\section{ACKNOWLEDGMENTS}

This study was supported by Universidad Técnica de Ambato, Ecuador (Project CPU-1373-2014-UTA) and (Project Canje de DeudaEspañaEcuador). This work has been reviewed in the English edition by Emilio Labrador.

\section{REFERENCES}

1. Chang SK, Alasalvar C, Bolling BW, Shahidi F. Nuts and their co-products: The impact of processing (roasting) on phenolics, bioavailability, and health benefits - A comprehensive review. J Funct Foods 2016;26:88-122.

2. Ros E. Health benefits of nut consumption. Nutrients 2010;2:652-82.

3. Ros E. Nuts and CVD. Br J Nutr 2015;113 Suppl 2:S111-20.

4. Jitngarmkusol S, Hongsuwankul J, Tananuwong K. Chemical compositions, functional properties, and microstructure of defatted macadamia flours. Food Chem 2008;110:23-30

5. Wallace HM. Walton 19 - Macadamia (Macadamia integrifolia, Macadamia tetraphylla and hybrids) A2 - Yahia, Elhadi M. Postharvest Biology and Technology of Tropical and Subtropical Fruits. Oxford: Woodhead Publishing; 2011. p. 450-74

6. Dahler JM, McConchie CA, Turnbull CG. Quantifi cation of cyanogenic glycosides in seedlings of three Macadamia (Proteaceae) species. Aust J Bot 1995;43:619-28.

7. Navarro SL, Rodrigues CE. Macadamia oil extraction methods and uses for the defatted meal byproduct. Trends Food Sci Technol 2016;54:148-54.

8. Monaghan K. Chemical Composition and Protein Antigenicity-Almond (Prunusdulcis) and Macadamia (Macadamia integrifolia) (PhD Degree Dissertation). Florida: Florida State University; 2008.

9. Maro LA, Pio R, Edos SP, Oliveira MC, Prates FC, Lima, LC, et al. Chemical characterization and fatty acids profile in macadamia walnut cultivars. Cien Rural 2012;42:2166-71.

10. INC. Macadamias. In: Nuts and Dried Fruits Nuts and Dried Fruits Global Statistical Review. Reus, Espanha: Inter Nut and Dried Fruit; 2014. p. 30-3.

11. Laohasongkram $\mathrm{K}$, Mahamaktudsanee $\mathrm{T}$, Chaiwanichsiri $\mathrm{S}$. Microencapsulation of Macadamia oil by spray drying. Proc Food Sci, 2011; 1:1660-5.

12. Vadivel V, Kunyanga CN, Biesalski HK. Health benefits of nut 
consumption with special reference to body weight control. Nutrition 2012;28(11-12):1089-97

13. Gutiérrez LF, Rosada LM, Jiménez A. Chemical composition of Sacha Inchi (Plukenetia volubilis L.) seeds andcharacteristics of their lipid fraction. Grasas Aceites 2011;62(1):76-83.

14. House SD, Larson PA, Johnson RR, DeVries JW, Martin DL. Gas chromatographic determination of total fat extracted from food samples using hydrolysis in the presence of antioxidant. J AOAC Int 1994;77:960-5

15. López-Miranda J, Pérez-Jiménez F, Ros E, De Caterina R, Badimón L, Covas MI, et al. Olive oil and health: Summary of the II International Conference on olive oil and health consensus report, Jaén and Córdoba (Spain) 2008. Nutr Metab Cardiovasc Dis 2010;20:284-94.

16. Huffman SL, Harika RK, Eilander A, Osendarp SJ. Essential fats: How do they affect growth and development of infants and young children in developing countries? A literature review. Matern Child Nutr 2011;7 Suppl 3:44-65.

17. Stevenson DG, Eller FJ, Wang L, Jane JL, Wang T, Inglett GE. Oil and tocopherol content and composition of pumpkin seed oil in 12 cultivars. J Agric Food Chem 2007;55(10):4005-13.

18. Theresia JJ, Austin PC, Kelly V, Mary A, Wei L, Joyce LK, et al. Evaluation of fattyacid and mineral content of Tanzanian seeds and oils. J Food Comp Anal. Available from: http://www.dx.doi.org/10.1016/j. jfca.2016.05.016.

19. Yoshida H, Tomiyama Y, Hirakawa Y, Mizushina Y. Variations in the composition of acyl lipids and triacylglycerolmolecular species of pumpkin seeds (Cucurbita spp.) followingmicrowave treatment. Eur J Lipid Sci Technol 2004;106(2):101-9.

20. Bernardo-Gil MG, Lopes, LM. Supercritical fluidextraction of Cucurbita ficifolia seed oil. Eur Food Res Technol 2004;219(6):593-7.

21. Yu W, Zhao Y, Chen J, Shu B. Comparison of twokinds of pumpkin seed oils obtained by supercritical CO2 extraction. Eur J Lipid Sci Technol 2004;106(6):355-8.

22. Applequist WL, Avula B, Schaneberg BT, Wang YH, Khan IA. Comparative fatty acid content of seeds of four Cucurbita species grown in a common (shared) garden. J Food Compos Anal 2006, 19 (6-7): 606-611.

23. Tsaknis J, Lalas S, Lazos ES. Characterization of crude andpurified pumpkin seed oil. Grasas Aceites 1997;48(5):267-72.

24. Kamel BS, de Man JM, Blackman B. Nutritional, fattyacid and oil characteristics of different agricultural seeds. J Food Technol 1982;17(2):263-9.

25. Gillingham LG, Harris-Janz S, Jones PJ. Dietary monounsaturated fatty acidsare protective against metabolic syndrome and cardiovascular disease risk factors. Lipids 2011;46(3):209-28.

26. Casas R, Sacanella E, Urpí-Sardà M, Corella D, Castañer O,
Lamuela-Raventos RM, et al. Long-term immunomodulatory effects of a mediterranean diet in adults at high risk of cardiovascular disease in the prevención con dieta mediterránea (PREDIMED) randomized controlled trial. J Nutr 2016;146:1684-93.

27. Panunzio MF, Caporizzi R, Antoniciello A, Cela EP, Ferguson LR, D'Ambrosio P. Randomized, controlled nutrition education trial promotes a Mediterranean diet and improves anthropometric, dietary, and metabolicparameters in adults. Ann Ig 2011;23(1):13-25.

28. Fuentes F, Lopez-Miranda J, Perez-Martinez P, Jimenez Y, Marin C, Gomez $\mathrm{P}$, et al. Chronic effectsof a high-fat diet enriched with virgin olive oil and a low-fat diet enriched withalpha-linolenic acid on postprandial endothelial function in healthy men. Br J Nutr 2008;100(1):159-65.

29. Hu FB, Satija A, Rimm EB, Spiegelman D, Sampson L, Rosner B, et al. Diet assessment methods in the Nurses' Health Studies and contribution to evidence-based nutritional policies and guidelines. Am J Public Health 2016;106(9):1567-72.

30. Venkatachalam M, Sathe SK. Chemical composition of selected edible nut seeds. J Agric Food Chem 2006;54:4705-14.

31. Phatanayindee S, Borompichaichartkul C, Srzednicki G, Craske J, Wootton M. Changes of chemical and physical quality attributes of Macadamia nutsduring hybrid drying and processing. Dry Technol 2012;30(16):1870-80.

32. Kaijser A, Dutta P, Savage G. Oxidative stability and lipid composition ofmacadamia nuts grown in New Zealand. Food Chem 2000;71(1):67-70

33. Firestone D, editor. In: Physical and Chemical Characteristics of Oils, Fats, and Waxes. Washington, DC: AOCS Press; 2006.

34. CFSAN/Office of Nutritional Products, L.A.D.S. Letter Responding to Health ClaimPetition dated August 28, 2003: Monounsaturated Fatty Acids from Olive Oil andCoronary Heart Disease (Docket No 2003Q0559); 2004

35. EFSA. Scientific Opinion on the substantiation of health claims related topolyphenols in olive and protection of LDL particles from oxidative damage (ID 1333, 1638, 1639, 1696, 2865), maintenance of normal blood HDL cholesterolconcentrations (ID 1639), maintenance of normal blood pressure (ID 3781), "anti-inflammatory properties" (ID 1882), "contributes to the upper respiratory tracthealth" (ID 3468), "can help to maintain a normal function of gastrointestinal tract"(3779), and "contributes to body defences against external agents" (ID 3467) pursuant to article 13(1) of regulation (EC) No 1924/2006. EFSA J 2011;9(4):2033-58

36. Bondia-Pons I, Schroder H, Covas MI, Castellote AI, Kaikkonen J, Poulsen HE, et al. Moderateconsumption of olive oil by healthy European men reduces systolic blood pressure in non-Mediterranean participants. J Nutr 2007;137(1):84-7. 